\title{
Optimizing effect of frying cycles on cooking oil properties using particle swarm optimization
}

\begin{abstract}
In this paper, Particle swarm optimization (PSO) technique has been proposed to evaluate the quality of recycled cooking palm oil. This technique proved to be the most powerful and robust technique in the modern era. The sensitivity of the threat by used cooking oil on public health and the complex nature and laborious approaches of evaluating the oil will be overcome through the proposed algorithm. The findings in this study have revealed that the appropriate temperature in degree centigrade $\left({ }^{\circ} \mathrm{C}\right)$, of grading cooking oil is higher than $200^{\circ} \mathrm{C}$ for both the TPC and FFA. The study also portrays none significant differences between PSO and GA in terms of optimum estimated value, fitness and temperature. The findings conclude that it is better to evaluate TPC and FFA of used oil at higher temperatures than at low temperatures.
\end{abstract}

